\title{
Endoscopic ultrasonography-guided obliteration of a left inferior phrenic artery pseudoaneurysm in a patient with alcoholic chronic pancreatitis
}

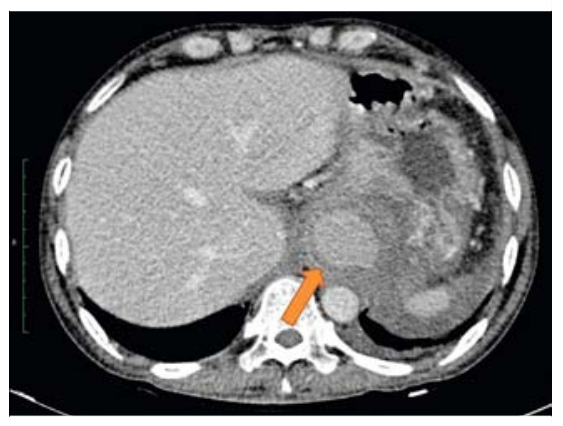

- Fig. 1 Contrast-enhanced computed tomography (CT) scan of the abdomen showing contrast extravasation (arrow) anterior to the descending aorta and a surrounding fluid collection.

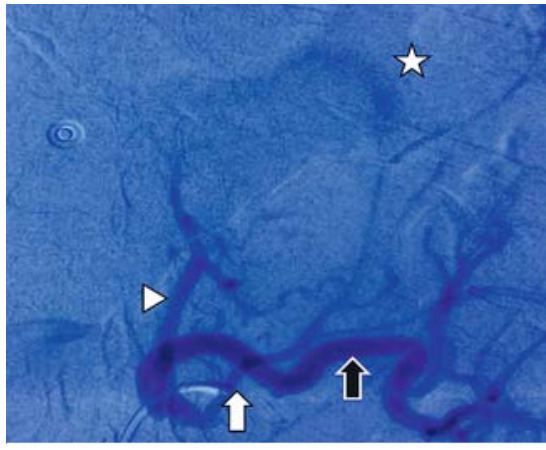

- Fig. 2 Digital subtraction angiography (DSA) of the celiac artery showing the splenic artery (black arrow), left gastric artery (arrowhead), and the left inferior phrenic artery (white arrow) with evidence of contrast extravasation (asterisk).

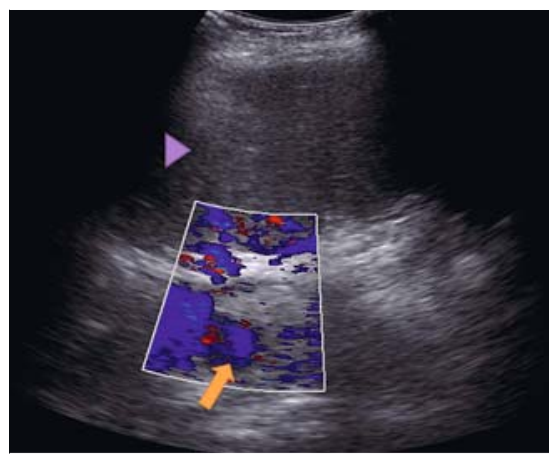

- Fig. 3 Doppler ultrasonography showing the pseudoaneurysm (arrow) deep to the splenic parenchyma (arrowhead).
A 43-year-old man who was known to have alcoholic chronic pancreatitis presented with upper gastrointestinal bleeding (UGIB) with shock in September 2016. He was resuscitated with crystalloids and a blood transfusion. He underwent gastroduodenoscopy, colonoscopy, and computed tomographic angiography (CTA), but no source of bleeding was revealed. He had a second episode of UGIB in December 2017. CTA on this occasion revealed contrast extravasation, probably from the left inferior phrenic artery (LIPA) (ฉ Fig.1). Digital subtraction angiography (DSA) confirmed the contrast leak from the LIPA ( $\triangleright$ Fig. 2) but embolization could not be performed owing to dissection of the artery during wire manipulation. Percutaneous thrombin (500 units) was therefore injected using a trans-splenic approach under Doppler ultrasonography guidance (>Fig.3) with subsequent thrombosis of the pseudoaneurysm.

The patient re-bled 1 month later and CTA showed a revascularized LIPA pseudoaneurysm. Because of the large size of the pseudoaneurysm and the previously failed DSA, endoscopic ultrasonography (EUS)-guided obliteration was planned. Linear EUS examination from the gastroesophageal junction showed a large pseudoaneurysm $(3.6 \times 2.3 \mathrm{~cm})$. The pseudoaneurysm was punctured with a 19-gauge needle (Echo-19; Cook India) and $3 \mathrm{~mL}$ undiluted $\mathrm{N}$-butyl 2-cyanoacrylate glue (NBCA) was injected to completely obliterate the pseudoaneurysm including the feeding vessel ( $\triangleright$ Video 1 ). There has been no recurrence of bleeding during the subsequent 9 months of follow-up.

Chronic pancreatitis-associated pseudoaneurysmal bleeding is well known. EUS has been reported as being useful both for the diagnosis and embolization of pseudoaneurysms [1]. The present case was unusual in many respects: (i) the involvement of the LIPA is rare with only one published report in chronic pancreatitis and the location of the pseudoaneurysm made it unsuitable for percutaneous intervention [2]; (ii) the pseudoaneurysm was large ( $>3 \mathrm{~cm}$ in size); and (iii) EUS-guided glue injection has been used infrequently. Because of the

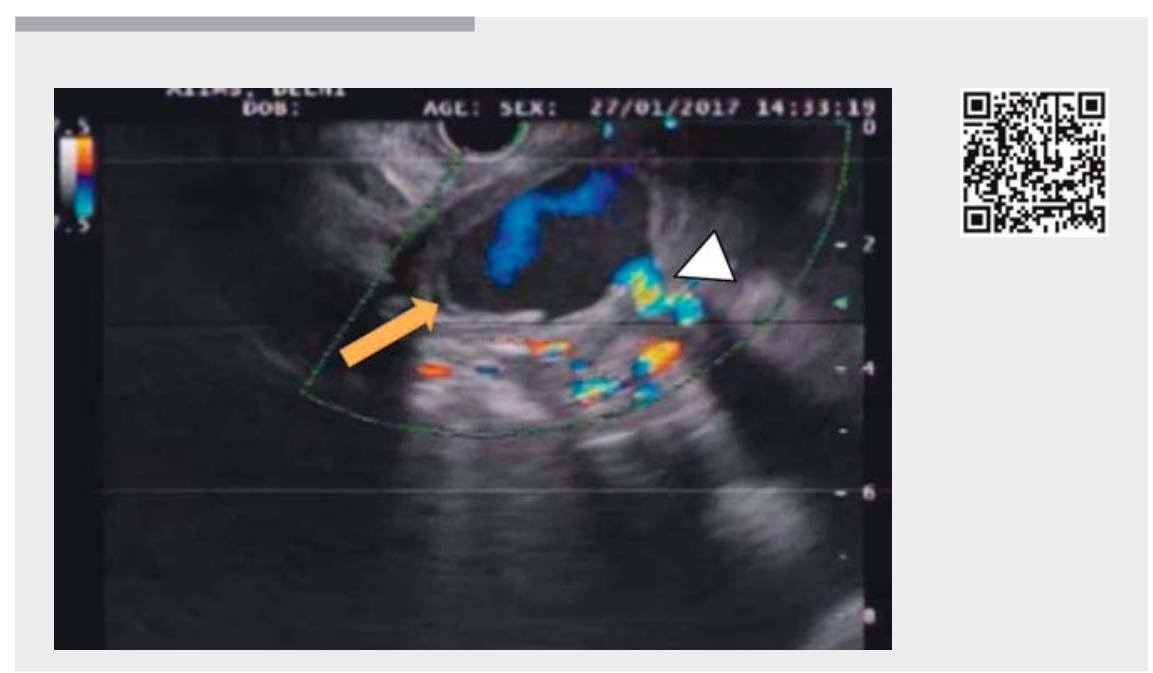

Video 1 Endoscopic ultrasonography-guided injection of N-butyl 2-cyanoacrylate glue with subsequent obliteration of the large left inferior phrenic artery pseudoaneurysm. 
technical difficulty during DSA, we resorted to EUS-guided NBCA injection to treat this patient's pseudoaneurysm [3].

Endoscopy_UCTN_Code_TTT_1AS_2AG

\section{Competing interests}

None

The authors

Deepak Gunjan ${ }^{1}$, Shivanand Gamanagatti ${ }^{2}$, Pramod Garg ${ }^{1}$

1 Department of Gastroenterology, All India Institute of Medical Sciences, New Delhi, India

2 Department of Radiodiagnosis, All India Institute of Medical Sciences, New Delhi, India

\section{Corresponding author}

\section{Pramod Garg, MD, DM}

Department of Gastroenterology, All India Institute of Medical Sciences, New Delhi, India

Fax: +91-11-26588663

pgarg10@gmail.com

\section{References}

[1] Gamanagatti S, Thingujam U, Garg P et al. Endoscopic ultrasound guided thrombin injection of angiographically occult pancreatitis associated visceral artery pseudoaneurysms: case series. World J Gastrointest Endosc 2015; 7: 1107-1113

[2] Arora A, Tyagi P, Gupta A et al. Pseudoaneurysm of the inferior phrenic artery presenting as an upper gastrointestinal bleed by directly rupturing into the stomach in a patient with chronic pancreatitis. Ann Vasc Surg 2012; 26: 860.e9-e11

[3] Gonzalez JM, Ezzedine S, Vitton V et al. Endoscopic ultrasound treatment of vascular complications in acute pancreatitis. Endoscopy 2009; 41: $721-724$

\section{Bibliography}

DOI https://doi.org/10.1055/s-0043-124867

Published online: 19.1.2018

Endoscopy 2018; 50: 449-450

(c) Georg Thieme Verlag KG

Stuttgart · New York

ISSN 0013-726X

\section{ENDOSCOPY E-VIDEOS}

https://eref.thieme.de/e-videos

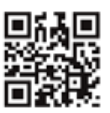

Endoscopy E-Videos is a free access online section, reporting on interesting cases and new

techniques in gastroenterological endoscopy. All papers include a high quality video and all contributions are freely accessible online.

This section has its own submission website at https://mc.manuscriptcentral.com/e-videos 